\title{
Semi-Automated Vehicle Routing System (SAVROS)
}

\author{
Saranga D. A. A. S. \\ Dias N. A. D. L. S. L. \\ Fernando K. A. G. C. \\ Senaviratna N. A. C. \\ Dhammearatchi D.
}

\begin{abstract}
Traffic congestion becoming the severe problem in most of the places of the world. From increased stress levels to serious national economical drawbacks and from time wastage to unrecoverable environmental issues. There are many traffic management and routing solutions have been researched ,developed and tested over and again , But still there are some areas that critically contribute to affect the efficiency of an any traffic system are not discussed and improved specially in traffic routing \& redirection, traffic plan updating, colour lights, traffic signs and infrastructure. Some of the systems that developed and proposed are based on much more technically advanced and sophisticated technologies but their solution and way they resolving the ultimate issue is poor. Even modern developed countries adopted those intelligent traffic routing systems to their road systems rarely due to above reason and economical and implementation issues. SAVROS is not only resolving the serious traffic congestion issues that most of the Peoples facing today but it introduces a procedure and smarter and economical way of managing the big picture of traffic management entirely .Due to above stated issues most of the countries including countries that have sophisticated road systems are still using traditional traffic management and routing mechanisms that is less efficient, need more time, cost and man power to manage and operate. SAVROS is basically consisted with a real-time embedded system connected to desktop application. Most of the traditional procedures and techniques will be replaced or improved and the system is designed to install in any existing traffic environment without making changes to them.
\end{abstract}

\section{Keywords}

Traffic Routing, Traffic congestion, Traffic control, Traffic flow Control, Embedded system

\section{INTRODUCTION}

According to US statistics report nearly $8 \%$ percent of life of an American is spent on the road due to traffic congestion, United States has the most developed road infrastructures comparing to other countries. It is undoubtable fact that the issue is in the way most of the countries used to overcome such issues.

There are factors that that critically affects the efficiency of any traffic management system.

Traffic routing, traffic redirection and traffic plan updating are the most critical factors among them. As stated earlier traffic flow is absolutely a set of natural incidents, those can't precisely measure or predicted in order to take optimal actions. Due to that reason traffic redirection, routing can't be done as an instant response to specific traffic incident. Therefore most of the traffic management mechanisms oriented on a fixed traffic plan for a specific region and changes are done rarely and less.

In traditional traffic control mechanisms changes are done through moving barriers, changing traffic signs etc. This way it needs more human resources, cost and time and it's absolutely not a real-time solution.

Currently the changes of traffic plans are documented manually and stored at relevant traffic police departments. This documentation task is also done by hand and this also prone to errors, important information can be missed and this needs more time, human resources, cost

Worst thing happens when the overwhelming the traffic flow than the road infrastructure or special incidents or natural disasters, so this kind of non-efficient systems would not be sufficient to full fill the traffic management requirements such as suggesting alternate paths, redirections and tactical traffic flow routing methods. So the solution would be a smart mechanism that can fulfil above requirements efficiently and can be used to manage existing traffic infesters in a real-time way.

Throughout this research project team implemented and introduced a full functional traffic routing mechanism that can be used in existing infrastructures without modifying them. The system built in low cost components and technologies, so the end product is not surprise to normal uses and they can use the system without any special technical knowledge.

System basically an embedded system that has a control panel and software interface. Control panel is a micro-controller that is connected to various kinds of input and output devices such as LED (light-emitting diode) sign panels, dynamic road surface markings, IR (infrared) sensors. Micro controller gets the input from the environment through input devices and takes necessary actions without or with human involvement. Actions are displayed through output devices such as dynamic sign in panels and road surface markings. If human involved it done through the software control panel. Basically the controlling and monitoring both could be done through the software control panel. To increase the strong connectivity between the control unit and the software interface, serial connectivity is used.

\section{BACKGROUND}

A There are lot of new efforts and research works done in the field of traffic control systems related. However there is significantly less research works and new inventions done for the automated vehicle routing, efficient traffic plan updating and traffic redirection. Most traditional automated systems based on mostly manual and more innovations are done for the improvements of traffic control systems rather than routing. There is the summery of the similar findings.

Road traffic control is one of the central topics of traffic control systems for whole world. In most of the countries there are lot of traffic congestion in the city areas on peak time. It is a huge time wasting and fuel consuming and also inefficient. To overcome those kinds of drawbacks, an innovative approach is required. SAVROS (Semi-Automated Vehicle 
Routing System) is consist of embedded system, connects to standalone application that assists traffic police units to manage various traffic related incidents. The system is consisting with the embedded road signs and IR sensors. Specially designed dynamic road sign boards and IR Sensors are positioned in predefined locations of the traffic infrastructure. If there is traffic in some area the system get data from the sensors and the system choose which is the shortest alternative path and the road sign blink the arrow to turn. And also alternative road is also block the embedded sign board display the "road is closed" sign. Likewise a single sign board can display many signs.

There has been research that is completely oriented on "smart highway" concept Scott and Burgaw J. (2001), innovation on "Solar Roadways" a next level traffic control system. [1] This system is implemented using self-powered led to dynamically display road surface markings such as centre lines, pedestrian crossings, dash-lines. This system had some practical and theoretical failures. Low-powered LED's used in this system has a view angle close to $20^{\circ}$. In this system they pointed and fixed this LED's vertically so this makes low visibility of light emitted by the LED to a viewer at from a lower angel.

Tragic accidents that may leads to loss of valuable lives can frequently occurred in school area, hill area and highways. There is a research to avoid such kind of accidents. It is a alerting for drivers to control their speed in such kind of places. So to intimate the driver about the zone and speed limit is done by RF (radio frequency) technology. The main part is Smart Display controller meant for vehicle's speed control and monitors the zones, which can run on an embedded system. Smart Display \& Control (SDC) can be fit into a vehicle's dashboard, and displays information on the vehicle. The project is composed of two separate units: zone status transmitter unit and receiver (speed display and control) unit. Once the information is received from the zones, the vehicle's embedded unit automatically alerts the driver, to reduce the speed according to the zone, it waits for few seconds, and otherwise vehicle's SDC unit automatically reduces the speed. [2]

Traffic in urban areas is mainly regularized by traffic lights, which may contribute to the unnecessary long waiting times for vehicles if not efficiently configured. This inefficient configuration is unfortunately still the case in a lot of urban areas, where most of the traffic lights are based on traditional systems. This system is implemented using video cameras. It will be able to determine three street cases (empty street case, normal street case and crowded street case) by using small associative memory. The system could determine all street cases with different weather conditions depending on the stream of images, which are extracted from the streets video cameras. By observation of the video cameras it is possible to control the traffic efficiently. This system will get high cost and very complicated. [3]

There is a system in Mumbai called Modern Traffic Management system. They are implementing video cameras in each and every street where traffic can be occurred. These cameras detect the intensity of the traffic and feed data into computers. This allows for real time adjustments of traffic signals that are synchronized to help commuters catch green lights all through and thus create an efficient traffic flow. Trouble spots can be tackled directly from the control center. Broken down vehicles or potential security risks or accidents can also be dealt with very quickly through continuous monitoring from the control center. [4]

Modern traffic management systems adapting image processing to identify incidents and control traffic. In this system camera is used to capture images of roads. Electronic sensors used to detect vehicles, and produce signal that cycles. The system will detect vehicles through images instead of using electronic sensors embedded in the pavement. Camera will be installed alongside the traffic light. It will capture image sequences. The image sequence will then be analysed using digital image processing for vehicle detection, and according to traffic conditions on the road traffic light can be controlled GSM (global System for Mobile) technique is used to handle emergency. [5]

\section{METHODOLOGY \\ 3.1 Identify Traffic Congestion}

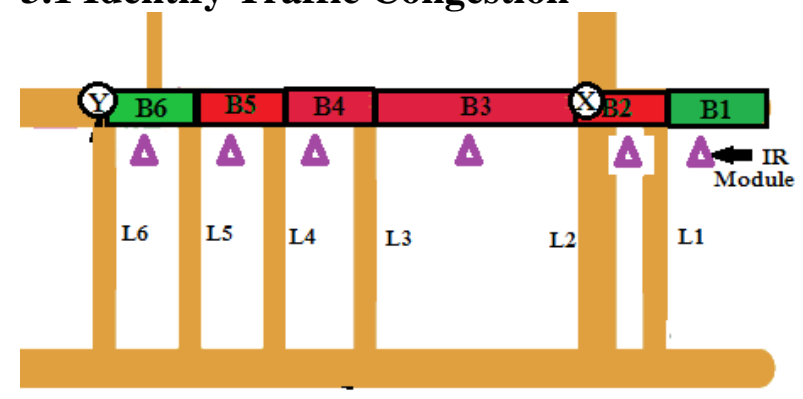

Fig. 1: IR sensors positioned in the road

IR Sensors positioned in predefined locations of the road infrastructure. IR sensors will be operates approximately $61 \mathrm{~cm}$ above from the road surface therefore every possible vehicle can be tracked. This kind of sensor set can be used to separate the road length into several portions. Each one of those portions called as blocks. When there is congestion IR sensors will blocked, because of this reason road block (portion) that is defined by respective IR sensor also considered as congested area.

Microcontroller starts to read the signals when one IR sensor blocked by the traffic or several IR sensors blocked by the traffic. When receive a signal and that represent a single IR sensor congestion, microcontroller starts a countdown. If the congestion ends before countdown, microcontroller automatically resets the countdown, if congestion remains after finishing the countdown; microcontroller identifies the start and end points of the congestion using the distance between IR sensors and start IR sensor position. After that those information will be sent to the software control panel through the serial interface.

When displaying the traffic status in the software control panel special kind of string will be processed in the microcontroller and that string will be continuously read through the serial communication.

Possible sample string that could generate when there is congestion can be illustrated as follows. Please not that between each one of those digits there will be a space character. Space character used in the software control panel to split the character string into digits. 
Table 1. Sensor 1 to sensor 5 congestion string

\begin{tabular}{|c|c|c|c|}
\hline $\begin{array}{c}\text { congestion } \\
\text { end point }\end{array}$ & $\begin{array}{c}\text { Congestion } \\
\text { Start point }\end{array}$ & $\begin{array}{c}\text { Traffic } \\
\text { plan } \\
\text { type }\end{array}$ & $\begin{array}{c}\text { Traffic } \\
\text { status }\end{array}$ \\
\hline 5 & 1 & 0 & 1 \\
\hline
\end{tabular}

\subsection{Measuring and displaying the traffic congestion length}

Specially processed character string that processed in the microcontroller continuously read through the serial communication. There are two separate digits in the character string that intended to define the start point and the end point of the traffic congestion. The values of the start, end points will be Varies 1 to $\mathrm{N}$ where $\mathrm{N}$ will be the number of sensors used to make the number of blocks.

Traffic congestion length will be calculated using the number of blocks/portions

Possible sample string that could generate when there is congestion can be illustrated as follows. (Please note that the congestion end point will always greater than the start point).

Table 2. Sensor 1 to sensor 4 congestion string

\begin{tabular}{|c|c|c|c|}
\hline $\begin{array}{c}\text { congestion } \\
\text { end point }\end{array}$ & $\begin{array}{c}\text { Congestion } \\
\text { Start point }\end{array}$ & $\begin{array}{c}\text { Traffic } \\
\text { plan } \\
\text { type }\end{array}$ & $\begin{array}{c}\text { Traffic } \\
\text { status }\end{array}$ \\
\hline 4 & 2 & 0 & 1 \\
\hline
\end{tabular}

Traffic length can be defined according to following equation.

(Traffic congestion length) $=1+($ congestion end point $)-$ (congestion start point)

According to above stated example traffic congestion length will be 3 blocks/portions. Software control panel will analyses that string and according to the value represented by the congestion

Table 3. Generate congestion string

\begin{tabular}{|c|c|c|c|}
\hline $\begin{array}{c}\text { congestion } \\
\text { end point }\end{array}$ & $\begin{array}{c}\text { Congestion } \\
\text { Start point }\end{array}$ & $\begin{array}{c}\text { Traffic } \\
\text { plan type }\end{array}$ & $\begin{array}{c}\text { Traffic } \\
\text { status }\end{array}$ \\
\hline$[1-6]$ & {$[1-6]$} & $0 / 1$ & $0 / 1$ \\
\hline $\begin{array}{c}\text { Depends on } \\
\text { number of } \\
\text { sensors }\end{array}$ & $\begin{array}{c}\text { Depends on } \\
\text { number of } \\
\text { sensors }\end{array}$ & $\begin{array}{c}\text { 1- not } \\
\text { default }\end{array}$ & 1-not ok) \\
\hline
\end{tabular}

Start and End points traffic status will be displayed in the software control panel.

\subsection{Automatic Redirection According to Congestion Nature}

Microcontroller initializes another counter at the same time of software control panel receiving the signal. If the user responded before countdown, microcontroller automatically resets the countdown. If user not responded within the countdown, microcontroller takes the control and decides the solution to resolve the problem.

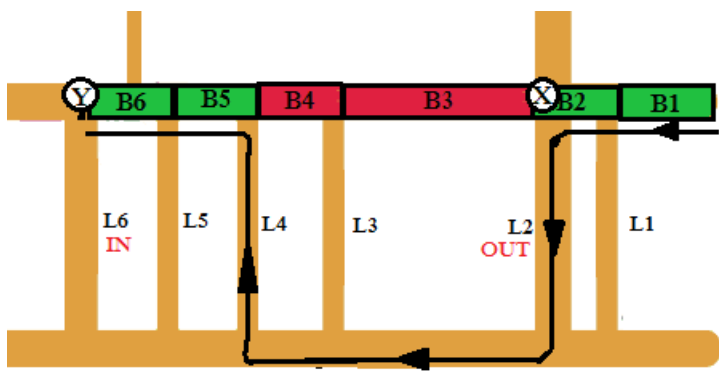

Fig. 2: Suggested alternate path

Please note that above diagram used to demonstrate how SAVROS suggest best alternate path when there is a congestion area in a road. When Block4 and Block 3 has traffic congestion,

Traffic flow from $\mathrm{X}$ to $\mathrm{Y}$ will be completely blocked because of B4, B3 portions are congested but traffic flow can be redirected from point $\mathrm{X}$ to $\mathrm{Y}$ using alternate path that illustrated in above diagram using arrows.

In such scenario, SAVROS will automatically does the redirection of traffic flow to alternate route and software control panel automatically highlights alternate path.

\subsection{Manual redirection of traffic flow}

System is built as a semi-automated utility; therefore traffic police can take the control and change the traffic plan even when there is no congestion or problem in the road. When there is congestion, a real-time notification will be displayed to inform about the congestion, in such situation traffic plan can be changed before count down. But even after the countdown, user can change the traffic plan using the software control panel. SAVROS always gives first priority to the user, therefore user can stay in default plan even when there is congestion. If default plan selected, microcontroller disable the counter and stops redirecting to alternate paths

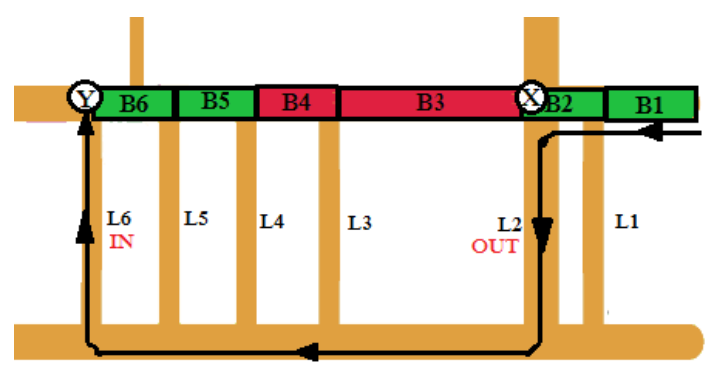

Fig. 3: Manual Redirection

Please note that above diagram used to demonstrate how SAVROS suggest best alternate path when there is a congestion area in a road. When Block4 and Block 3 has traffic congestion,

Traffic flow from $\mathrm{X}$ to $\mathrm{Y}$ will be completely blocked because of B4, B3 portions are congested but traffic flow can be redirected from point $\mathrm{X}$ to $\mathrm{Y}$ using alternate path that illustrated in above diagram using arrows. Through L2 (Lane 2) block traffic flow is going out from the main road and again through L6 (Lane 6) traffic flow is coming back to the main road. System takes the inputs as IN/OUT Lanes and signal will be sent to the microcontroller to commit the redirection. 


\subsection{Updating the traffic plan / keep track changes}

Each and every change that committed to the master traffic plan will be precisely tracked according to the timestamp and stored in the RDBMS (real time database management system) without any loss of information.

When making an update to the traffic plan SAVROS software control panel processes a string according to the inputs given and that signal will be written via serial communication to the microcontroller. Storing the relevant information in the RDBMS is also will be done as a parallel process to the serial write

\subsection{Dynamic LED Sign Panel}

Nowadays most of the traffic light systems use LED diodes. The reason is they are 10 times more efficient than incandescent light traffic lights. And the clarity of the shape is much better with LED diodes even in higher distances. Commonly used

FX200 series traffic light is clearly visible up to 300 meters

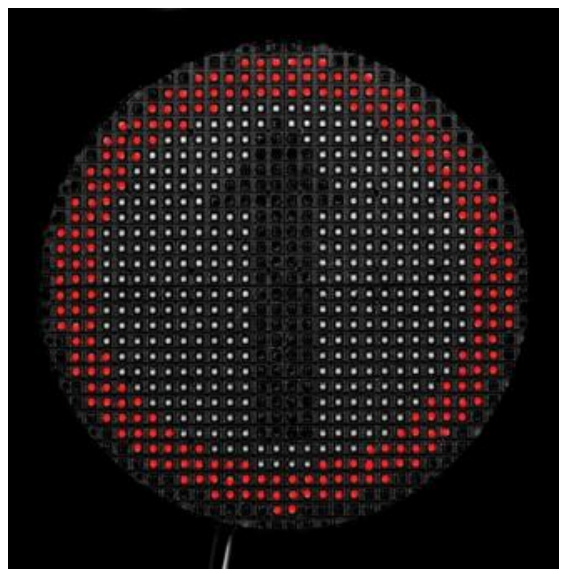

Fig. 4: LED dynamic panel

When traffic flows without an issue the sign board can display relevant sign. When the road is jammed the sign board can use to close the road or redirect vehicles to alternative roads

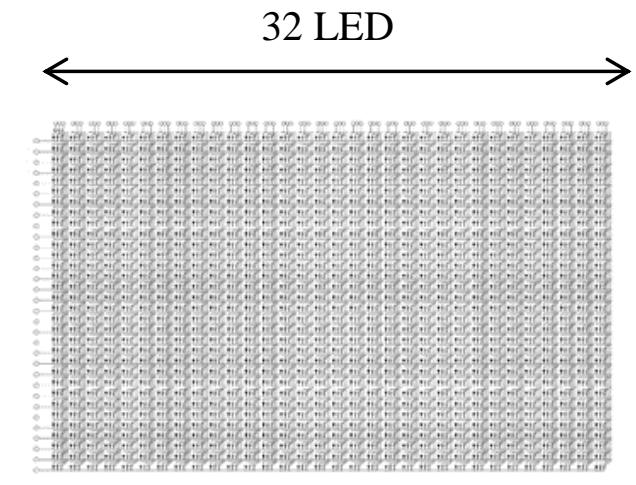

Fig. 5: LED dynamic structure

Dynamic traffic sign is 1024 pixel $5 \mathrm{~mm}$ pitch Display. Lower distance between pixels (pitch) is used to clearly visible the road sign from lower distance to medium distance.

- $\quad$ pixel - single LED in the panel

- $\quad$ pitch - distance between two LEDs

RGB LED can emit red, green and blue lights separately.
There is a minimum visible frame rate for human eye. When the frame rate higher than that, brain does not identify the gap between frames. This phenomenon is used in CRT (cathode ray tube) colour monitors to show different colour pixels using Red Green and Blue colour generating electron guns.

The same methodology is used in this LED matrix. We use Red Green and Blue colours to display various colours by lighting them separately but with very high frequency. In one cycle of lighting 3 colours, by changing the duration for each colour it can create different colours.

\subsection{Dynamic LED Pathway}

LED diode has a narrow view angle of $8^{\circ}-20^{\circ}$. The result is it works well with outdoor sign boards. But most of the diode LEDs has less than $5000 \mathrm{mcd}$. And with the lower view angle and low brightness they are not practice when using with digital pathways.

mcd - mill candelas (a measurement that can use to measure the brightness of a low power LED)

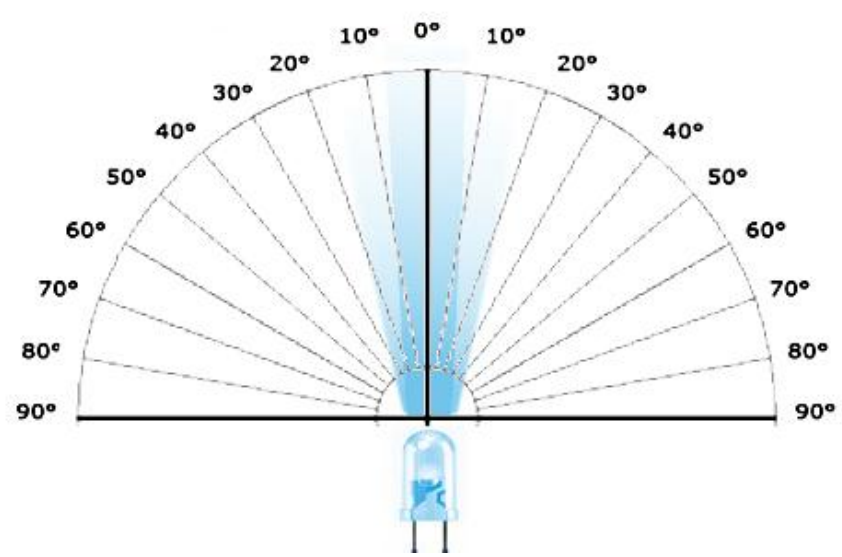

Fig. 6 LED Diode view angle

High power LEDs are working well with Digital pathways when light rays are directed to the right angle.

Design of the tempered glass road reflector which uses total internal reflection as the reflection method will be used for Digital pathway Indicators.

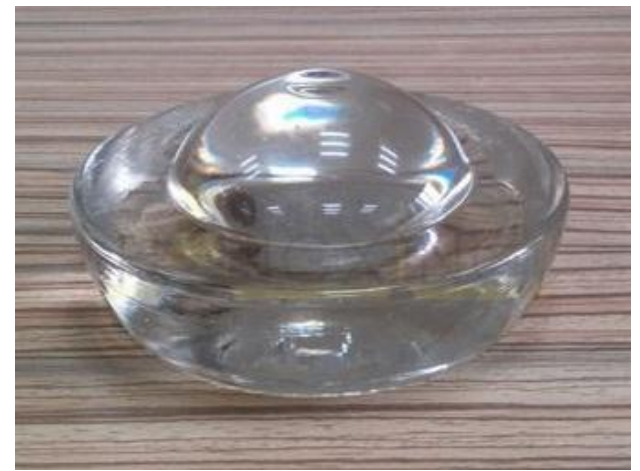

Fig. 7: Tempered glass road reflector 


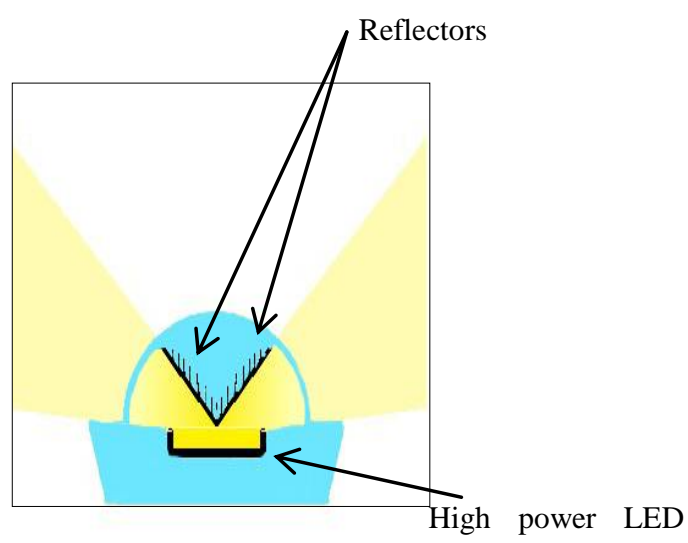

Fig. 8: Pathway design

Cross selection of light travel in Dynamic Pathway Indicator. 10W LED chip with 900 lumens will be used for pathway indicator with $30^{\circ}$ reflection.

Which is equals to 4203.7 candela ( 840.6 times brighter than LED diode)

Table 4. Luminous intensity calculation

candela $=$ lumens $/(2 \pi(1-\cos ($ degrees $/ 2)))$

\section{RESEARCH FINDINGS AND EVIDENCE}

According to the traffic congestion nature, micro controller genarates a specific character string to represent specific informatiion. This string pattern can be illustrated as follows.

Software control panel is continuesly reading this string value thruogh the serial interface and analyse it. When there is any congestion/traffic block, it will be represented by the char "1" and if there is no such congestion or traffic block it will be represented by the char value "0". Software control panel will analyses that string and according to the value represented by the traffic status relevant notification will be displayed.

Table 5. Detect Congestion According to Signal

\begin{tabular}{|c|c|c|c|}
\hline $\begin{array}{l}\text { congestion } \\
\text { end point }\end{array}$ & $\begin{array}{l}\text { Congestion } \\
\text { Start point }\end{array}$ & $\begin{array}{c}\text { Traffic } \\
\text { plan } \\
\text { type }\end{array}$ & $\begin{array}{l}\text { Traffic } \\
\text { status }\end{array}$ \\
\hline 4 & 2 & 0 & 1 \\
\hline $\begin{array}{l}\text { Depends } \\
\text { on number } \\
\text { of } \\
\text { sensors }\end{array}$ & $\begin{array}{l}\text { Depends on } \\
\text { number of } \\
\text { sensors }\end{array}$ & $\begin{array}{c}0- \\
\text { default } \\
1-\text { not } \\
\text { default }\end{array}$ & $\begin{array}{c}0 \text {-ok / } \\
1-\text { not } \\
\text { ok }\end{array}$ \\
\hline [1-6] & [1-6] & {$[0-1]$} & {$[0-1]$} \\
\hline
\end{tabular}

this notification displayed in the login view form as well as every interface of the software control panel.

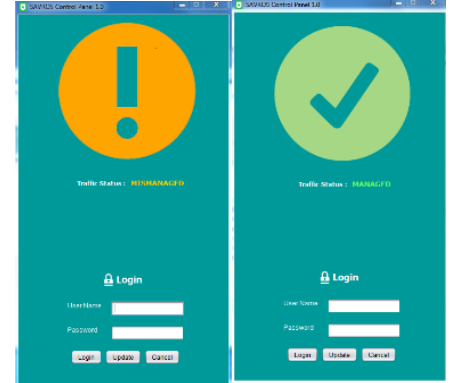

Fig.9: Notification in the login view

SAVROS will automatically does the redirection of traffic flow to alternate route and software control panel automatically highlights alternate path as shown in figure below.

According to the figure below block2 to block4 illustrated as blocked.

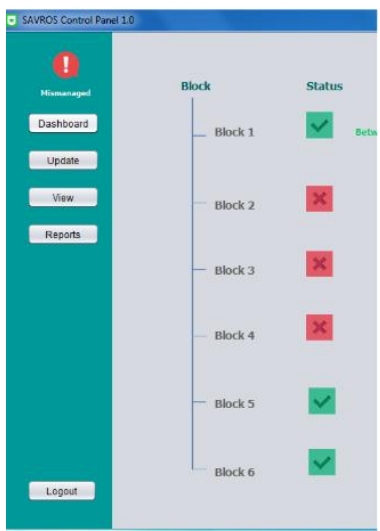

Fig.10: Traffic length

Each and every change that committed to the master traffic plan will be precisely tracked according to the timestamp and stored in the RDBMS without any loss of information. Update $\log$ is displayed as given

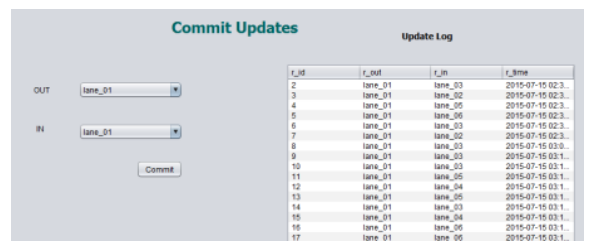

Fig.11: Traffic plan updating tracked

\section{CONCLUSION AND FUTURE WORKS}

A novel, simple, recuperated and low cost system for increase the efficiency of the traffic system was introduced and implemented through this research. SAVROS system solved the most critical problems that affected the efficiency of an any traffic system through introducing novel way of routing and redirecting, also real time traffic plan updating concept. Traffic related components such as traffic signs, road surface markings and traffic light systems were improved without making changes to the original perception and meaning of them. LED dynamic matrix and digital pathways can be stated as examples.

Future development will be mostly oriented on the improving the usability of the system. There should be a trustworthy wireless communication instead of wired connection 
throughout the site of operation. In this regard, the system is more economical and simple. Future research could focus deeper into the particular areas which had identified in information gathering and development. System maintenance is much more complicated than these specified factors because it requires much more effort. Web application based software control panel would be more benefited comparative to standalone application. If the system built on above approach server has more processing to be done instead of two tiers architecture three tier architecture would be more efficient. Because every calculation is being done by the server is very crucial and should be accurate, efficient and convenient. Using IR sensors to detect the traffic congestion will occur some reliability issues; therefore introducing an image processing oriented CCTV (Closed-circuit television) traffic detection mechanism would be more effective. Efficient image processing algorithms will be required to detect the congestion precisely. Controller unit would be expanded to high-end capacity to increase the efficiency of the whole operation.

Efficient and Safety transportation plays a significant role when considering major developments of a country and it is a very important fact which every country ought to have gained in order to obtain the fully developed status. Project SAVROS will going to be a worthy system to improve the efficiency and the safety of the road of Sri Lanka as well as the future road development projects of all over the world.

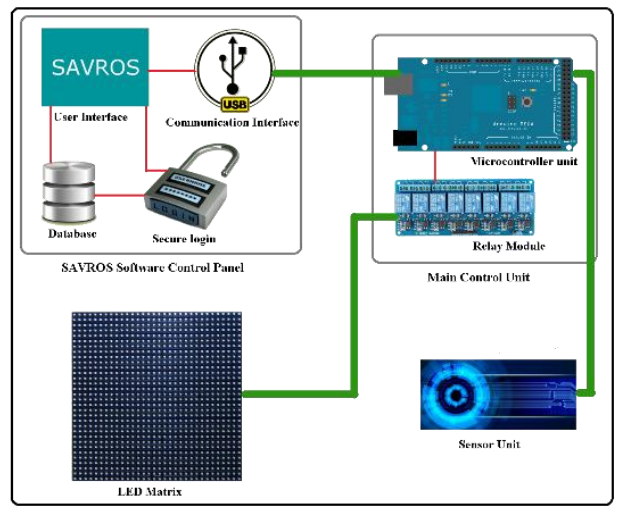

Fig.12: Architecture Diagram

\section{REFERENCES}

[1] Alcantarilla P.F., Sotelo M.A., et al. Automatic Daytime Road Traffic Control and Monitoring System. [OnlineAvailable]www.robesafe.es/personal/bergasa/pap ers/ITSC_Alcantarilla_2008.pdf [accessed 25 January, 2015]

[2] Scott and Brusaw J., Solar Roadways. [Online Available] http://www.solarroadways.com/about.shtml, [Accessed on 23 January, 2015]

[3] Tan C. H., Zegeer C. V., European Practices and Innovations for Pedestrian Crossings. [Online Available],http://citeseerx.ist.psu.edu/viewdoc/download? doi $=10.1 .1 .374 .5204 \&$ rep=rep1\&type $=$ pdf, [Accessed on 25 January, 2015]

[4] Houten R.V., Retting R.A. et al, Use of Animation in LED Pedestrian Signals to Improve Pedestrian Safety. [OnlineAvailable],http://citeseerx.ist.psu.edu/viewdoc/do wnload?doi=10.1.1.417.3659\&rep=rep1\&type=pdf, [accessed26 January, 2015]

[5] Krogh C., Irgens M., et al, A Novel Architecture for Traffic Control. [OnlineAvailable],http://citeseerx.ist.psu.edu/viewdoc/do wnload?doi=10.1.1.46.3583\&rep=rep1\&type=pdf, [Accessed on 26 January, 2015]

[6] Marchesini P., Weijermars W., The relationship between road safety and congestion on motorways. [Online Available], http://www.swov.nl/rapport/R-2010-12.pdf, [Accessed on 26 January, 2015]

[7] Sellinger M., Schmidt P.L., Adaptive Traffic Control Systems in the United State. [Online Available], http://www.hdrinc.com/sites/all/files/assets/knowledgecenter/articles/adaptive-traffic-control-systems-in-theunited-states-2010.pdf, [Accessed on 26 January, 2015] 